\title{
Lysosomal enzyme abnormalities in preleukaemic Sweet's disease: case report
}

\author{
M JUDGE,* S E MOSS, $\dagger$ G T N BESLEY, $\dagger$ A C PARKER*
}

From the Department of *Haematology, Royal Infirmary, Edinburgh, and the $†$ Department of Pathology, Royal Hospital for Sick Children, Edinburgh

SUMMARY Quantitative and qualitative abnormalities in marrow lysosomal enzymes, suggestive of acute myeloid leukaemia, were detected in a patient with Sweet's disease and monocytosis 12 months before she presented with acute myelomonocytic leukaemia. Biochemical characterisation of blood and marrow cell extracts may help to identify those patients with Sweet's disease and other preleukaemic conditions who are most at risk of developing leukaemia.

Sweet's disease or acute febrile neutrophilic dermatosis, first described in $1964,{ }^{1}$ has distinctive clinical and histological features. It occurs mainly in middle aged women and presents with systemic upset, fever in about $50 \%$ of patients, and an asymmetric eruption, which progresses over some weeks from erythematous patches on the forearms, face, and legs to painful red-brown plaques that may ulcerate. The process untreated lasts up to two months but may recur, and over half of such patients have a neutrophil leucocytosis at some time. ${ }^{2}$ Histologically there is a dense perivascular neutrophil infiltrate in the dermis but no abscess formation and no granulation tissue.

In 1973 the first report of an association between Sweet's disease and acute leukaemia was published, ${ }^{3}$ and it is now estimated that roughly $10 \%$ of patients with Sweet's disease have an associated myeloproliferative or leukaemic condition diagnosed before, simultaneously, or following the skin disease, the commonest being acute myeloid leukaemia of M4 and M5 type. ${ }^{4}$ As this is a preleukaemic condition it is wise to carry out regular haematological checks in patients with Sweet's disease. This may not be practical, however, and is unlikely to change the natural course of events in patients who have transformed.

Biochemical analysis of blood and marrow leucocytes has led to the recognition of consistently abnormal patterns of lysosomal enzyme activity in haematological malignancy. ${ }^{5-7}$ By combining the results of enzyme activities and expression for a number of different lysosomal enzymes, specific patterns of abnormality are obtained that correlate well with various types of leukaemia. The technique can also be

Accepted for publication 30 June 1986 applied to patients with preleukaemic conditions. The methods used here are as previously described. ${ }^{8}$

\section{Case history}

A 60 year old woman with Sweet's disease was referred for assessment to the haematology clinic in October 1983. She had had moderately severe rheumatoid arthritis (seronegative) for 10 years and was taking eight aspirin tablets daily. Sweet's disease confirmed by biopsy was diagnosed in September 1983 when she presented with nodular erythema of the upper arms, face, and legs. Though a similar rash had occurred intermittently over the preceding six years, fever was never documented. Clinically she was well, and peripheral blood findings were as follows: haemoglobin $7 \cdot 7 \mathrm{~g} / \mathrm{dl}$, mean cell volume $68 \mathrm{fl}$, white cell count $10.9 \times 10^{9} / 1$, neutrophils $46 \%$, lymphocytes $41 \%$, monocytes $13 \%$, platelets $275 \times 10^{9} / 1$. Erythrocyte sedimentation rate was $65 \mathrm{~mm} /$ first hour. There was no obvious source of blood loss, and faecal occult blood tests yielded negative results. The marrow aspirate was hypercellular due to myeloid hyperplasia, and myeloid maturation was normal. There was no monocytosis and no evidence of leukaemia or myelodysplastic syndrome. Erythropoiesis was micronormoblastic and iron stones were absent. Dual esterase staining showed more than $95 \%$ chloroacetate esterase positivity. Marrow leucocyte lysosomal enzyme profile was abnormal, with a pronounced increase in $\beta$-hexosaminidase activity, a slight rise in $\alpha$-mannosidase activity, and a low B peak on isoelectric focusing of $\beta$-hexosaminidase (table and figure). This pattern is similar to that seen in patients with acute myeloid leukaemia. ${ }^{5}$ Trephine biopsy of the iliac crest showed reactive changes with 
Table Lysosomal enzyme activities (with normal ranges) in leucocytes (nmol/minute per $\mathrm{mg}$ protein)

\begin{tabular}{lcl}
\hline Samples & $\beta$-Hexosaminidase & $\alpha$-Mannosidase \\
\hline a Marrow Oct 1983 & $43(25 \cdot 4 \pm 5 \cdot 8)$ & $7 \cdot 0(4 \cdot 6 \pm 1 \cdot 8)$ \\
b Blood Jan 1985 & 119 & 7.4 \\
c Blood May 1985 & 89 & 6.0
\end{tabular}

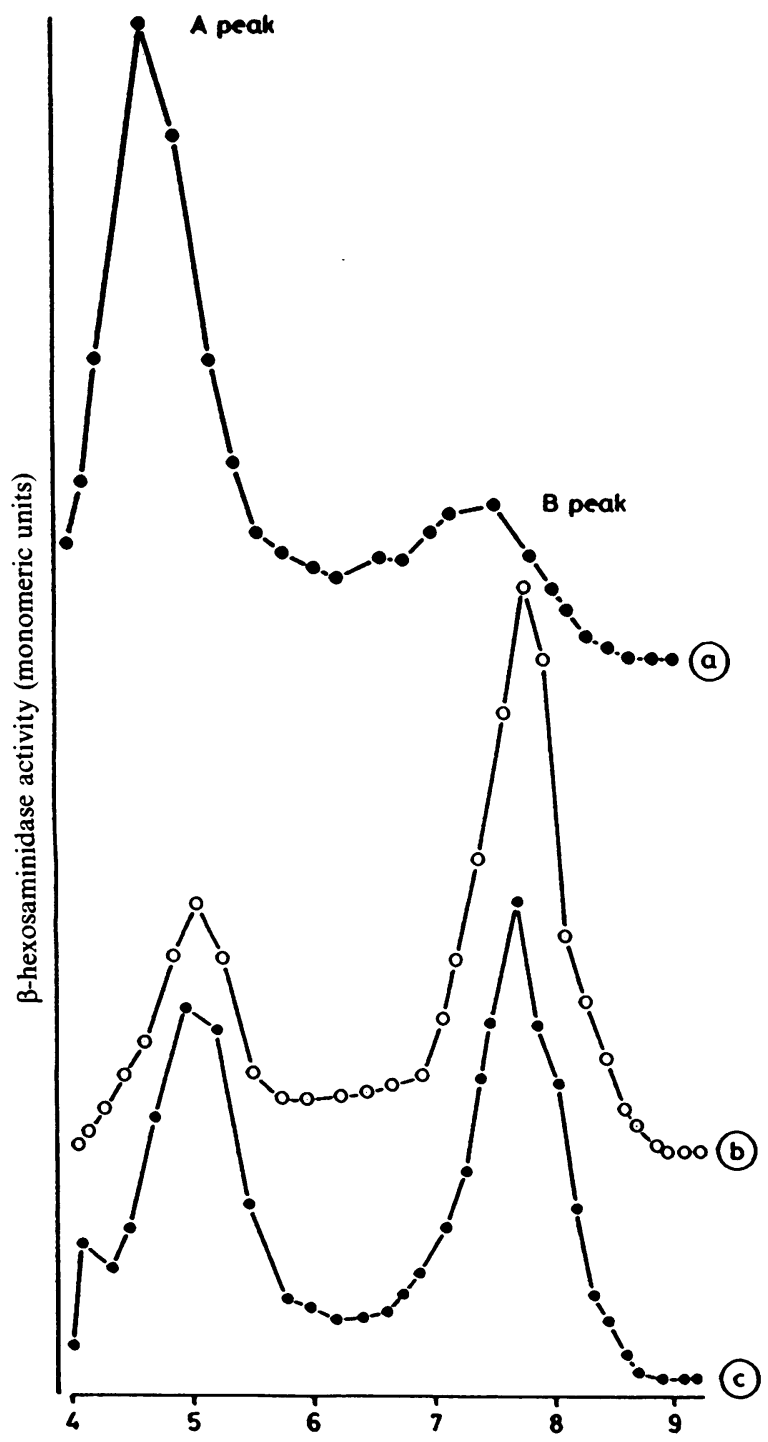

Figure Isoelectric focusing profiles of $\beta$-hexosaminidase in one patient. Enzyme activities (fluorimetric units) are plotted against fraction $p H$. Samples are: $a=$ presentation; $b=$ relapse of $A M M O L ;$ and $c=$ florid $A M M O L$. They correspond to values given in table. focal hypercellularity and prominent early myeloid forms with full maturation.

The skin lesions resolved within five weeks of starting steroids. The aspirin was stopped and the anaemia responded to iron tablets. Three months later a full blood count showed a haemoglobin concentration of $11.9 \mathrm{~g} / \mathrm{dl}$, white cell count $14.4 \times 10^{9} / 1$, neutrophils $57 \%$, lymphocytes $25 \%$, monocytes $18 \%$ and platelets $175 \times 10^{9} / 1$

In October 1984 she presented with a four week history of weight loss and vomiting. There was active synovitis of the left knee, elbows, and fingers but no evidence of Sweet's disease. A full blood count showed a haemoglobin of $10 \cdot 2 \mathrm{~g} / \mathrm{dl}$, white cell count $65 \times 10^{9} / 1$, monocytoid blasts $44 \%$, neutrophils $21 \%$, lymphocytes $11 \%$, monocytes $22 \%$, platelets $292 \times 10^{9} / 1$. The marrow was hypercellular with a $64 \%$ infiltrate of monoblasts; cytochemical staining indicated a myelomonocytic leukaemia. Intensive chemotherapy induced a short lived remission and relapse was treated with palliative chemotherapy. A transient nodular rash of the arms and legs was shown histologically to be due to leukaemic infiltration.

The lysosomal enzyme activity on peripheral blood leucocytes again showed the pattern of acute myeloid leukaemia, but the profile now resembled that seen in acute myelomonocytic leukaemia with reversal of the $A$ to $B$ ratio of $\beta$-hexosaminidase. (sample b).

She remained clinically well on palliative chemotherapy and supportive treatment until September 1985 when she had a major intracranial bleed.

\section{Discussion}

Sweet's disease is a preleukaemic condition of unknown aetiology. A few patients develop leukaemia, but for those with normal haematological studies there is no marker that identifies those most at risk. Lysosomal enzyme abnormalities may help in identifying these patients before clinical disease is evident. Distinctive patterns of abnormality have been identified in leukaemias of myeloid, monocytic, and lymphoid origin. In one study $\beta$-hexosaminidase was considerably raised in all patients with monocytic and myelomonocytic leukaemia, with less pronounced rises seen in acute myeloid leukaemia. ${ }^{5}$

Alpha-mannosidase activity was raised in some patients with monocytic leukaemia and reduced in all with lymphoid leukaemias. ${ }^{5}$ Using isoelectric focusing, the hexosaminidase B isoenzyme was reduced in patients with acute myeloid leukaemia regardless of the level of total enzyme. In contrast, patients with common acute lymphoblastic leukaemia have raised intermediate isoenzyme, and the absolute activity of 
enzyme does not correlate with the marrow blast count. $^{6}$

The monocytosis present on initial presentation in our patient suggests the existence of a myelodysplastic condition or early chronic myelomonocytic leukaemia, and the initial marrow showed myeloid hyperplasia with a lysosomal enzyme profile consistent with a myeloid abnormality.

The lysosomal enzyme patterns in patients with myelodysplasia and chronic myelomonocytic leukaemia have not been studied, but in view of their leukaemic potential and in the light of this case these studies might identify the high risk group early on. Interestingly, this laboratory has also detected an acute myeloid leukaemia type pattern of lysosomal enzymes in a patient with Hodgkin's disease who had been successfully treated with chemotherapy and radiotherapy some years before. He developed acute myeloid leukaemia 12 months later. This reinforces the suggestion that typical patterns of lysosomal enzyme abnormality can be helpful, not only in the classification of established leukaemias, but also in predicting leukaemic transformation in patients with primary and secondary myelodysplasias as well as in Sweet's disease.

We are indebted to Dr Edna Dewar, pathology department, University of Edinburgh, for her help and advice and to Mrs Lorna Greig for secretarial assistance. We also acknowledge the support of the Cancer Research Campaign.

\section{References}

1 Sweet RD. An acute febrile neutrophilic dermatosis. $\mathrm{Br} J$ Dermatol 1964;76:349-56.

2 Sweet RD. Acute neutrophilic dermatosis. 1978. Br J Dermatol 1979;100:93-9.

3 Matta M, Malak J, Tabet K, et al. Sweet's syndrome: systemic associations. Cutis 1973;12:561-5.

4 Aram H. Sweet's syndrome response to dapsone. Arch Dermatol 1984;120:245-7.

5 Besley GTN. Correlation of lysosomal enzyme abnormalities in various forms of adult leukaemia. J Clin Pathol 1983; 36:1000-4.

6 Blatt J. Current concepts. Biochemical markers in lymphoid malignancy. N Engl J Med 1980;303(16):918-22.

7 Drexler HG. Biochemical enzyme analysis in acute leukaemia. J Clin Pathol 1985;38:117-27.

8 Broadhead DM. Recognition of abnormal lysosomal enzyme patterns in childhood leukaemia by isoelectric focusing, with special reference to some properties of abnormally expressed components. Leuk Res 1981;5:29-40.

Requests for reprints to: Dr AC Parker, Department of Haematology, Royal Infirmary, Lauriston Place, Edinburgh EH3 9YW, Scotland. 